\title{
Conformational analysis of the telomerase RNA pseudoknot hairpin by Raman spectroscopy
}

\author{
VYTAS REIPA, ${ }^{1}$ GEDIMINAS NIAURA, ${ }^{2}$ and DONALD H. ATHA ${ }^{\mathbf{1}}$ \\ ${ }^{1}$ Biochemical Science Division, National Institute of Standards and Technology, Gaithersburg, Maryland 20899-8311, USA \\ ${ }^{2}$ Organic Chemistry Department, Institute of Chemistry, 2600 Vilnius, Lithuania
}

\begin{abstract}
We have measured the temperature-dependent Raman spectra of two 30-mer ribonucleotides that represent the wild-type (WT) and dyskeratosis congenita (DKC) mutant (MT) GC (107-108) $\rightarrow$ AG structures of the pseudoknot hairpin region of human telomerase RNA. We have used these structures, previously characterized by UV-melting and NMR, as a model system for our Raman investigation. We observe that Raman hypochromism of vibrational bands, previously assigned to specific bases or conformational RNA markers, reflect temperature-dependent alterations in the pentaloop and stem structures of these two oligonucleotides. We also observe that the intense $v_{\mathrm{s}}(\mathrm{O}-\mathrm{P}-\mathrm{O})$ band at $812 \mathrm{~cm}^{-1}$ indicates the presence of A-form backbone structure at relatively low temperatures in both the WT and MT RNA sequences. The mutation induces a decrease in the intensity of the uridine ( $\mathrm{rU})$ band at $1244 \mathrm{~cm}^{-1}$ associated with $\mathrm{C} 2$ ' -endo/anti ribose conformation in the pentaloop. Two transition temperatures $\left(T_{m}\right)$ were determined from the analysis of Raman difference intensity-temperature profiles of the $1256 \mathrm{~cm}^{-1}$ band, which is associated with vibrations of cytidine $(\mathrm{rC})$ residues, in particular, the C2' -endo/anti ribose conformation $\left(T_{m} 1=23.6 \pm 1.6^{\circ} \mathrm{C}\right.$ for $\mathrm{WT}$ and $19.7 \pm 2.8^{\circ} \mathrm{C}$ for $\mathrm{MT} ; T_{m} 2=68.9 \pm 1.8^{\circ} \mathrm{C}$ for $\mathrm{WT}$ and $70.9 \pm 1.1^{\circ} \mathrm{C}$ for $\left.\mathrm{MT}\right)$. From these results we can conclude that the DKC mutant 30-mer exhibits a lower stability in the pentaloop region and a slightly higher stability in the stem region than the WT 30-mer. This demonstrates that Raman bands, previously assigned to specific bases or conformational RNA markers, can be used to probe local structural features of the telomerase pseudoknot hairpin sequence.
\end{abstract}

Keywords: telomerase; RNA conformation; RNA pseudoknot hairpin; Raman spectroscopy

\section{INTRODUCTION}

Raman spectroscopy is a well-established technique that has been successfully utilized in the structural characterization of nucleic acids. Earlier studies have established the relationship between double-helical structures and Raman band frequencies (Benevides and Thomas 1983; Thomas and Peticolas 1983), providing the basis for conformational

Abbreviations: WT, wild type; DKC, dyskeratosis congenita; MT, mutant; $\mathrm{rU}$, uridine nucleotide; rC, cytidine nucleotide; $T_{m}$, melting transition temperature; PAGE, polyacrylamide gel electrophoresis.

Certain commercial equipment, instruments, materials, or companies are identified in this paper to specify adequately the experimental procedure. Such identification does not imply recommendation nor endorsement by the National Institute of Standards and Technology, nor does it imply that the materials or equipment identified are the best available for the purpose.

Reprint requests to: Donald $H$. Atha, Biochemical Science Division, NIST, 100 Bureau Drive, Gaithersburg, MD 20899-8311, USA; e-mail: donald.atha@nist.gov; fax: (301) 975-8505.

Article published online ahead of print. Article and publication date are at http://www.rnajournal.org/cgi/doi/10.1261/rna.182607. marker bands. Experiments with model compounds and theoretical normal-mode calculations have enabled Raman band assignment to specific regions of the double helix. Subsequent studies have confirmed this method as a sensitive probe of phosphodiester torsion angles, sugar pucker, stacking geometry, and hydrogen bonding (Thomas and Tsuboi 1993; Thomas 1999). Temperature-dependent Raman can be used to follow structural transitions anticipated by UV melting curves but with much higher informational content. A recent series of investigations of ultrastable RNA tetraloops have established a Raman marker database that can be used for analysis of other structures such as internal loops or bulges (Abdelkafi et al. 1997a; Leulliot et al. 1999a; Baumruk et al. 2001).

In this study we have conducted temperature-dependent Raman studies of two 30-mer ribonucleotide hairpin sequences, representing both wild-type (WT) and dyskeratosis (DKC)-mutant (MT) hairpin structures of the pseudoknot region of human telomerase (see Fig. 1) We chose these particular structures as a model system in our 


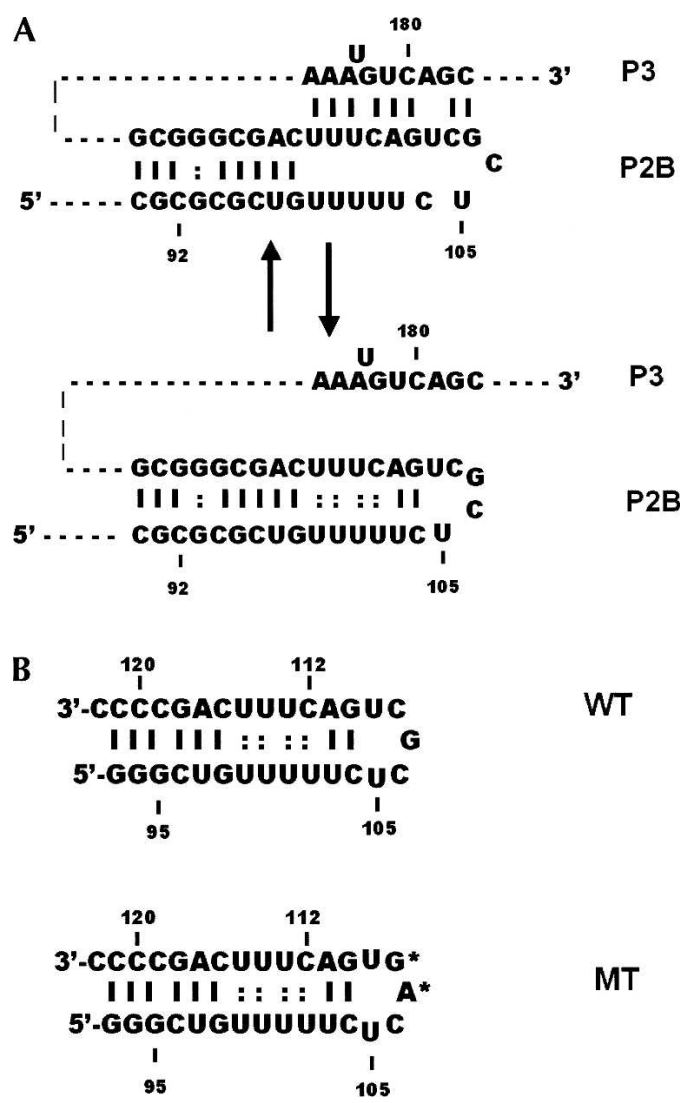

FIGURE 1. Secondary structure of the pseudoknot domain of human telomerase RNA and the WT and DKC-MT hairpin oligonucleotides used in this study. (A) The pseudoknot domain is shown from a previously proposed model of two conformational states in which there is an interaction between the P2B hairpin and P3 regions (Comolli et al. 2002; Theimer et al. 2003a,b, 2005). (B) The WT and DKC-MT oligonucleotides used in the current study. The DKC mutation GC (107-108) $\rightarrow$ AG is indicated by an asterisk $\left.{ }^{*}\right)$.

Raman analysis since they have been well characterized by UV and NMR and exhibit conformational changes that are of considerable biological importance. We have used the Raman hypochromism of vibrational bands, previously assigned to specific bases or conformational RNA markers (Benevides and Thomas 1983; Thomas and Peticolas 1983; Thomas and Tsuboi 1993; Abdelkafi et al. 1997a; Leulliot et al. 1999a; Thomas 1999; Baumruk et al. 2001) to probe the pentaloop and stem regions of these two previously characterized structures (Comolli et al. 2002; Theimer et al. 2003a,b, 2005).

Telomerase is a reverse transcriptase of great interest to the medical community because of its association with cancer. It is expressed in $85 \%-90 \%$ of all human cancers, but not in most normal nonstem somatic tissues (Kim et al. 1994). Telomerase catalyzes the end capping of chromosomes (telomeres) with the repetitive DNA sequence motif, in vertebrates (TTAGGG) (Blackburn 1991; Allsopp et al. 1992). The enzyme has been isolated from human cells in complexes ranging from 500 to $1500 \mathrm{kDa}$. Four distinct conserved structural domains have been identified in the RNA component of vertebrate telomerase: the pseudoknot (CR2/CR3), the CR4/CR5, the BoxH/ACA, and the CR7 domain (Chen et al. 2000). Studies have also shown that the pseudoknot (CR2/CR3) and CR4/CR5 domains are required for vertebrate telomerase activity (Martin-Rivera and Blasco 2001). Subsequently, a molecular switch model has been proposed that involves an equilibrium between two conformational states of the pseudoknot, which affects telomerase activity and can be altered by RNA mutations such as those that occur in dyskeratosis congenita (Comolli et al. 2002; Theimer et al. 2003a,b, 2005) (see Fig. 1). However, a more recent study does not support this model (Chen and Greider 2005).

NMR and UV spectroscopy have previously been used to monitor the effect of RNA mutations within the pseudoknot domain, which are associated with dyskeratosis congenita (Comolli et al. 2002; Theimer et al. 2003a,b, 2005). NMR coordinates of the P2b (Theimer et al. 2003a,b) and P2b-P3 (Theimer et al. 2005) regions of the pseudoknot domain, available through the PDB protein data bank, have been used as a guide in constructing three-dimensional molecular models of the WT and MT hairpin (Theimer et al. 2003a,b; Yingling and Shapiro 2005) and pseudoknot (Theimer et al. 2005) domains. In the present study we show how Raman band thermal transitions can be correlated with previous analyses of these structures. In addition, we show how Raman can yield additional structural information that can help evaluate current models of the telomerase RNA pseudoknot.

\section{RESULTS AND DISCUSSION}

\section{Structural assignments of vibrational features}

In this study we have focused on two spectral intervals, $760-840 \mathrm{~cm}^{-1}$ and $1200-1275 \mathrm{~cm}^{-1}$, which are free from any contribution of buffer species and contain critical structural information about base stacking, structure of $\mathrm{rC}, \mathrm{rU}$ residues, sugar pucker sensitive modes and stem secondary structure markers (Abdelkafi et al., 1997b, 1998; Leulliot et al. 1999b; Baumruk et al. 2001). Figure 2 compares the Raman spectra of the WT and MT RNA observed at two extreme temperatures $\left(2.5^{\circ} \mathrm{C}\right.$ and $\left.85^{\circ} \mathrm{C}\right)$ in the $760-840 \mathrm{~cm}^{-1}$ frequency range. Two clearly defined bands located at $\sim 784 \mathrm{~cm}^{-1}$ and $812 \mathrm{~cm}^{-1}$ are visible in the low temperature spectrum (Fig. 2A). Polarization measurements (data not shown) have shown that both bands are polarized and, thus, belong to totally symmetric vibrational modes. The $784-\mathrm{cm}^{-1}$ peak can be reliably assigned to pyrimidine ring breathing modes of $\mathrm{rC}$ and rU residues (Trulson et al. 1987; Thomas and Tsuboi 1993; Leulliot et al. 1999b). In order to account for the relative contribution of the $\mathrm{rC}$ and $\mathrm{rU}$ residues we have measured the Raman spectra of pure cytidine- $5^{\prime}$-monophosphate and 


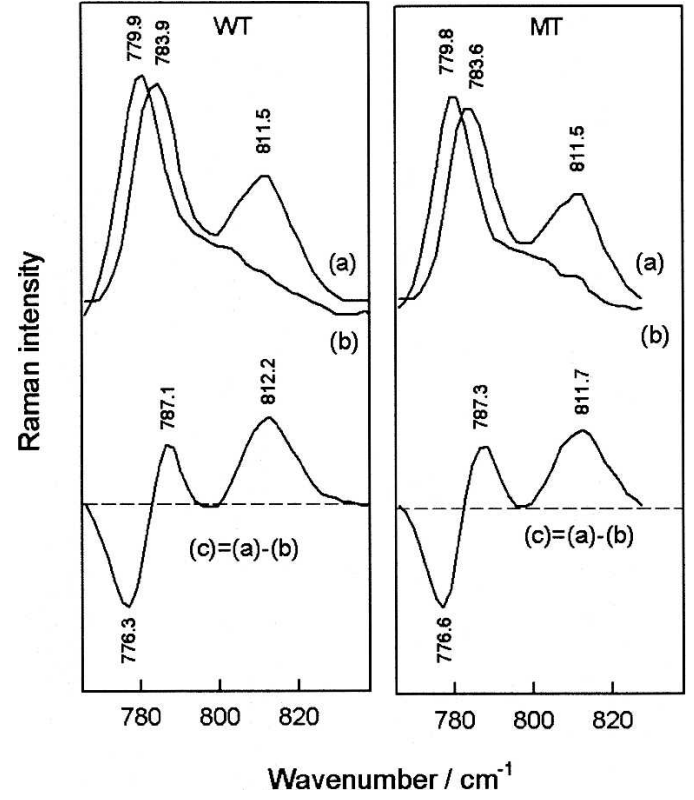

FIGURE 2. Raman spectra $\left(\lambda_{\mathrm{exc}}=647.1 \mathrm{~nm}\right)$ of WT and DKC-MT hairpins of the human telomerase RNA measured in the 760-840 $\mathrm{cm}^{-1}$ spectral region at two extreme temperatures. (A) $2.5^{\circ} \mathrm{C}$. (B) $85^{\circ} \mathrm{C}$. The difference spectra are shown in $C$.

uridine- $5^{\prime}$-monophosphate at $10 \mathrm{mM}$ in phosphate buffer solution and have normalized the intensities of $784 \mathrm{~cm}^{-1}$ bands to the intensity of water bending $\delta(\mathrm{HOH})$ mode. The relative contribution of $\mathrm{rU}$ residues to the intensity of ring breathing mode at $784 \mathrm{~cm}^{-1}$ is $\sim 24 \%$ for the WT oligonucleotides that contain $11 \mathrm{rU}$ and $10 \mathrm{rC}$ residues. For DKC-MT that has $11 \mathrm{rU}$ and $9 \mathrm{rC}$ residues, this value increases to $27 \%$. Thus, the majority of the $784 \mathrm{~cm}^{-1}$ band intensity comes from the $\mathrm{rC}$ residues in both nucleotides. Position of this band shifts to lower wave numbers by $\sim 11-12 \mathrm{~cm}^{-1}$ upon deuteration at imino $(\mathrm{N} 3 \mathrm{H})$ or amino $\left(\mathrm{N}_{4} \mathrm{H}_{2}\right)$ sites of uridine and cytidine rings, respectively ( $\mathrm{Li}$ et al. 1993); hence, it is sensitive to hydrogen bonding interactions. Also, earlier studies have shown that intensity of this mode increases upon base unstacking, a so-called Raman hypochromism effect (Small et al. 1972; Baumruk et al. 2001). The second peak located at $\sim 812 \mathrm{~cm}^{-1}$ (Fig. $2 \mathrm{~A})$ derives its intensity primarily from the phosphodiester group, $v_{\mathrm{s}}(\mathrm{O}-\mathrm{P}-\mathrm{O})$ symmetric stretching $\mathrm{O}-\mathrm{P}-\mathrm{O}$ vibrational mode (Small et al. 1972; Trulson et al. 1987; Dohy et al. 1989; Abdelkafi et al. 1998). In addition, this mode is coupled with C3'-endo ribose vibrations (Small et al. 1972). An important feature of this mode is its sensitivity to the backbone conformation. It was shown that $v_{\mathrm{s}}(\mathrm{O}-\mathrm{P}-\mathrm{O})$ band could be used as a marker of A-form RNA (Small et al. 1972; Trulson et al. 1987). Observation of $\nu_{\mathrm{s}}(\mathrm{O}-\mathrm{P}-\mathrm{O})$ peak at $812 \mathrm{~cm}^{-1}$ in our low temperature $\left(2.5^{\circ} \mathrm{C}\right)$ spectra (Fig. $2 \mathrm{~A}$ ) provides direct evidence of $\mathrm{A}$-form backbone structure in both WT and DKC MT nucleotides. Similar $v_{\mathrm{s}}(\mathrm{O}-\mathrm{P}-\mathrm{O})$ band frequencies, half-widths, and intensities suggest that DKC mutation (GC (107-108) $\rightarrow$ AG) does not perturb stem secondary structure in the $\mathrm{P} 2 \mathrm{~b}$ hairpin at low temperatures.

Upon temperature increase to $85^{\circ} \mathrm{C}$ (Fig. 2B) we have recorded several perturbations of these Raman bands: (a) the $v_{\mathrm{s}}(\mathrm{O}-\mathrm{P}-\mathrm{O})$ band intensity is markedly reduced, $(\mathrm{b})$ the frequency of the ring breathing mode $\left(784 \mathrm{~cm}^{-1}\right)$ shifts to lower wave numbers, and gains in intensity. These changes are highlighted in the difference spectra (Fig. 2C), where positive and negative features indicate decrease and increase of the corresponding peak intensities at high temperature, respectively. Complete disappearance of the A-form backbone marker band $\nu_{\mathrm{s}}(\mathrm{O}-\mathrm{P}-\mathrm{O})$ at higher temperature (Fig. 2B) points to extensive conformational changes in the environment of the phosphodiester site due to the loss or weakening of the hydrogen bonding interaction between bases, while intensity gains for the regular stem structure. Frequency shift of the breathing ring mode mainly reflects that this mode is characteristic of the base unstacking.

The spectral region between $1200-1275 \mathrm{~cm}^{-1}$ (Fig. 3) contains vibrational features characteristic for $\mathrm{rU}$ and $\mathrm{rC}$ residues, which are sensitive to ribose conformation. The spectral contour is complex due to overlap of several close bands (Fig. 3A). In order to enhance spectral resolution, we have calculated second derivatives of the experimental

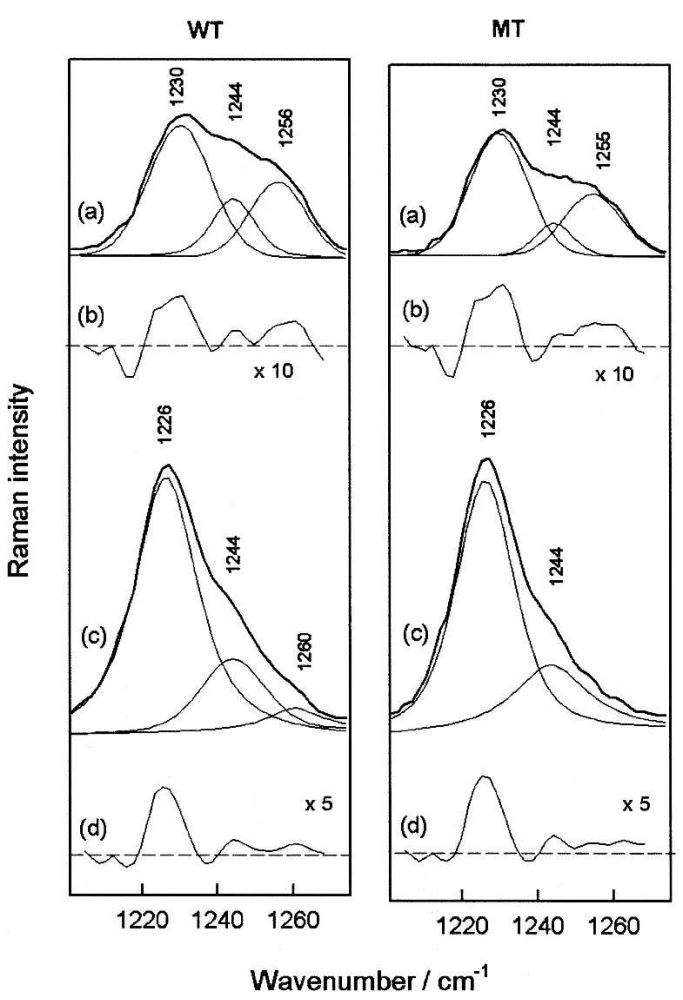

FIGURE 3. Raman spectra $\left(\lambda_{\text {exc }}=647.1 \mathrm{~nm}\right)$ of WT and DKC $-\mathrm{MT}$ hairpins of the human telomerase RNA measured in the $1200-1275 \mathrm{~cm}^{-1}$ spectral region. (A) $2.5^{\circ} \mathrm{C}$. (C) $85^{\circ} \mathrm{C}$. The corresponding derivatives (multiplied by -1 ) are shown $(B, D)$. Band deconvolution using Gaussian-Lorentzian line shapes is presented in $A$ and $C$ (thin lines). 
spectra (Fig. 3B,D). In this way, three main peaks can be resolved at $1230 \mathrm{~cm}^{-1}, 1244 \mathrm{~cm}^{-1}$, and $1255-1256 \mathrm{~cm}^{-1}$ in the low-temperature derivative spectra (Fig. 3B). The $1244-\mathrm{cm}^{-1}$ peak is slightly better resolved in WT sample spectrum than in the MT. It should be noted that the most intense $1230-\mathrm{cm}^{-1}$ peak contains a low-frequency side shoulder at $\sim 1225 \mathrm{~cm}^{-1}$. Band profiles were used for digital decomposition of the experimental contour into the mixed Gaussian-Lorentzian components (Fig. 3A,C, thin lines). The dominant $1230-\mathrm{cm}^{-1}$ peak in this spectral region can be reliably assigned to the characteristic inplane stretching vibration of the $\mathrm{rU}$ residues in $\mathrm{C} 3{ }^{\prime}$-endo/ anti conformation (Benevides and Thomas 1983). Pronounced hypochromism of this peak (Fig. 3C) mainly originates from the destacking of U103 and U97 residues in the A-form stem at elevated temperature. The second component located at $1244 \mathrm{~cm}^{-1}$ reflects two contributions: the vibrations of $\mathrm{rC}$ residues located in stem while in $\mathrm{C} 3{ }^{\prime}$-endo/anti conformation, and loop $\mathrm{rU}$ residues while in C2'-endo/anti conformation (Abdelkafi et al. 1998; Leulliot et al. 1999a). Intensity of this component increases with temperature (Fig. 3C). It should be emphasized that the intensity of the $1244-\mathrm{cm}^{-1}$ peak in the low-temperature spectrum is higher for the WT sample compared with the MT (Fig. 3A). This effect is clearly pronounced in the difference spectrum when the WT spectrum is subtracted from the MT spectrum (Fig. 4A).

The negative feature at $1242 \mathrm{~cm}^{-1}$ is clearly expressed in the differential spectra (Fig. 4A). Divergence in $1244 \mathrm{~cm}^{-1}$ component intensity for the WT and MT samples points to the dissimilar conformation of the pentaloop $\mathrm{rU}$ residues. Specifically, loss of the $\mathrm{C} 2$ '-endo/anti conformation upon mutation is strongly suggested. We propose that one of

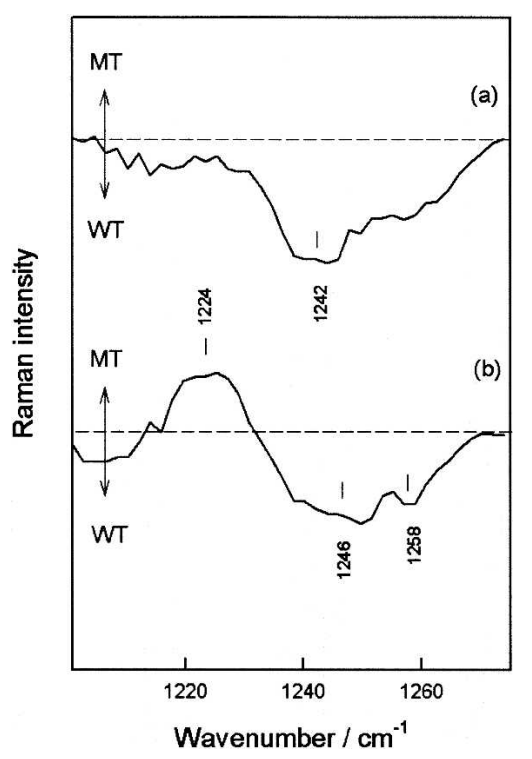

FIGURE 4. Difference Raman spectra of WT and DKC-MT hairpins at $2.5^{\circ} \mathrm{C}(A)$ and $85^{\circ} \mathrm{C}(B)$ in the $1200-1275 \mathrm{~cm}^{-1}$ spectral region. the $\mathrm{rU}$ residues in the pentaloop transforms from $\mathrm{C}_{2}^{\prime}$ endo/anti to $\mathrm{C} 3{ }^{\prime}$-endo/anti conformation due to the GC (107-108) $\rightarrow$ AG mutation. Indeed, the published solution structures of the $\mathrm{p} 2 \mathrm{~b}$ hairpin from human telomerase RNA (PDB IDs 1NA2 and 1Q75) confirm our prediction. Residue U109 in the pentaloop changes from $\mathrm{C}_{2}$ '-endo/ anti in the WT to $\mathrm{C}^{\prime}{ }^{\prime}$-endo/anti in the MT sequence. Also, possible conformational switches of the U105, U109 bases in the DKC-mutated hairpin structure were recently discussed in the structural analysis of WT and MT telomerase RNA by molecular dynamics simulation (Yingling and Shapiro 2005). In this work it was suggested that U105, C106, and U109 are rather flexible, and are intermittently switching between syn and anti conformations. The third peak at $1256 \mathrm{~cm}^{-1}$ is assigned to the loop $\mathrm{rC}$ vibrational mode that adopts $\mathrm{C} 2{ }^{\prime}$-endo/anti ribose conformation. This band is more intense in the WT sample (Figs. 3, 4), possibly reflecting one extra $\mathrm{C}$ nucleotide at position 108 that is replaced by G108 in the MT. Intensity of the $1256 \mathrm{~cm}^{-1}$ peak is significantly reduced in the high temperature spectra, reflecting conformational transformations during loop melting (Fig. 3).

\section{Thermodynamic stability of the hairpin structure}

Raman spectroscopy provides the possibility to study the temperature-induced perturbations in RNA structure by tracking band intensities and positions. The decrease in Raman intensity due to gradual denaturation is called hyperchromicity, while the opposite effect is known as hypochromicity. Qualitative and quantitative information about global conformation of nucleic acids can be obtained from measurement of Raman melting curves in the same way as in UV absorbance melting experiments. However, Raman spectroscopy can also provide information about thermal behavior of the localized structural segments, as hairpin stem and loop. First, we will discuss the stability of a stem structure.

Figure 5 shows the evolution of the differential Raman intensity of the $\nu_{\mathrm{s}}(\mathrm{O}-\mathrm{P}-\mathrm{O})$ mode at $812 \mathrm{~cm}^{-1} \Delta I=I_{\mathrm{T}}-I_{2.5}$ (where $I_{\mathrm{T}}$ is the intensity at temperature $T$, and $I_{2.5}$ is Raman intensity at $2.5^{\circ} \mathrm{C}$ ) with the temperature. As already discussed, this vibrational mode serves as a marker band for the A-form backbone structure. The negative sign of the $\Delta I$ indicates that intensity of this band declines at higher temperatures, most likely due to conformational perturbation of the phosphodiester groups and loss of the hairpin stem global A-form structure. Transition temperatures $\left(T_{m}\right)$ determined from the fitted curves (Fig. 5, solid lines) were found to fall in the same interval $(55.9 \pm 4.1$ and $51.6 \pm$ $1.1^{\circ} \mathrm{C}$ for WT and MT RNA, respectively) within the limits of experimental uncertainty, indicating in general the same stability of the A-form structure in both WT and MT samples. Still, the higher $T_{m}$ recorded for the WT sample is consistent with UV melting studies (Comolli et al. 2002) 


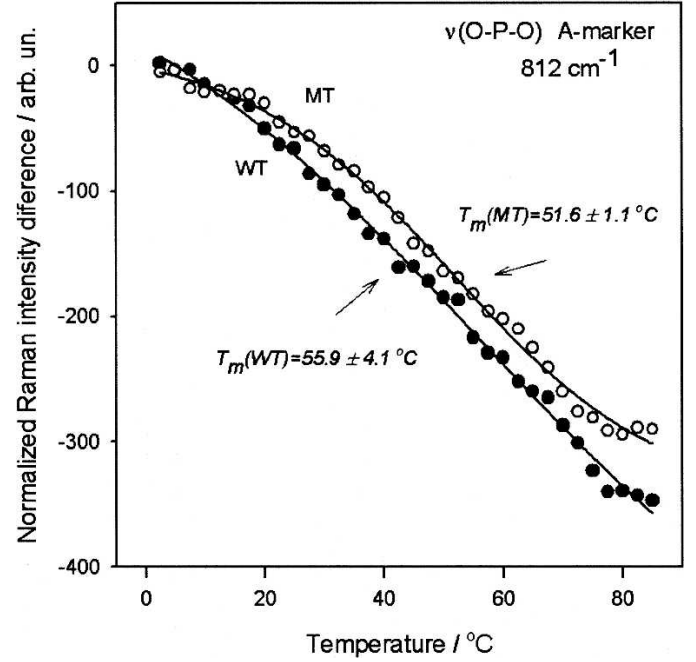

FIGURE 5. Temperature-dependent profiles of $812 \mathrm{~cm}^{-1}$ band, associated with an A-form marker $\nu_{\mathrm{s}}(\mathrm{O}-\mathrm{P}-\mathrm{O})$ phosphodiester vibrational mode for the WT (filled circles) and DKC-MT (open circles) hairpin forming RNA oligonucleotides. Solid lines represent the fitted curves. Differential Raman band intensities were calculated by subtracting the spectrum obtained at $2.5^{\circ} \mathrm{C}$ from the spectrum recorded at the particular temperature.

where the stem domain melting transition was assigned using NMR spectroscopy.

Pyrimidine ring interaction upon base stacking provides the physical basis for Raman hypochromism of the 782$\mathrm{cm}^{-1}$ band, assigned to the uracil and cytosine ring breathing mode. Loss of base stacking upon temperature increase results in less ring interaction and translates into higher Raman intensity (Fig. 6). Band intensity change accelerates above $\sim 40^{\circ} \mathrm{C}$ for the WT oligonucleotides, while for the DKC-MT sample it tends to increase at lower $\left(\sim 20^{\circ} \mathrm{C}\right)$ temperatures. Analysis of fitted curves revealed a slightly higher transition temperature for the WT (52.7 \pm $\left.1.3^{\circ} \mathrm{C}\right)$ compared with MT $\left(49.5 \pm 1.5^{\circ} \mathrm{C}\right)$ RNA. As the majority of $\mathrm{rC}$ residues, primarily responsible for the hypochromism of the $782-\mathrm{cm}^{-1}$ band, are located in the stem (C96, C116, C119, C120, C121), it is apparent that DKC mutation slightly destabilizes the stacking interaction between the stem region $\mathrm{rC}$ and $\mathrm{rG}$ residues.

Comparable melting temperatures $\left(52.1 \pm 1.5^{\circ} \mathrm{C}\right.$ and $48.9 \pm 1.0^{\circ} \mathrm{C}$ for $\mathrm{WT}$ and MT samples, respectively) were also obtained from the analysis of the band positions at different temperatures (Fig. 7). Band position could be estimated with high precision when the experimental contour is decomposed (Fig. 2) into components of mixed Lorentzian-Gaussian shape. The frequency of this vibrational mode is primarily affected by $\mathrm{H}$-bonding interactions. Therefore, an observed frequency decrease reflects weakening of the $\mathrm{H}$-bonding interaction at the pyrimidine ring imino $(\mathrm{N} 3 \mathrm{H})$ and amino $\left(\mathrm{N}_{4} \mathrm{H}_{2}\right)$ sites.

The peak at $1230 \mathrm{~cm}^{-1}$ exhibits remarkable hypochromism (Fig. 3) and, therefore, was used to construct the intensity-temperature profiles (Fig. 8), which provides information on stacking interaction of uridine nucleotides adopting $\mathrm{C} 3^{\prime}$-endo/anti sugar pucker. The melting temperatures $\left(T_{m}=47.3 \pm 0.7^{\circ} \mathrm{C}\right.$ and $44.2 \pm 0.6^{\circ} \mathrm{C}$ for the WT and MT samples, respectively) as determined from the fitted curves, are on average lower by $\sim 5^{\circ}$ than the characteristic transition temperature derived from $782-\mathrm{cm}^{-1}$ band intensity that represents hairpin stem cytidine nucleotides (Fig. 6). Apparently stacking interactions for $\mathrm{rU}$ residues are weaker as suggested in the noncanonical stem region (Comolli et al. 2002; Yingling and Shapiro 2005). The lower $T_{m}$ obtained for the DKC-MT, relative to the WT hairpin structure, actually indicates mutation-induced destabilization of stacking interaction between the U103 and A111 rings.

Temperature effects on hairpin loop structure were analyzed through the temperature-intensity profiles of the $1256-\mathrm{cm}^{-1}$ band (Fig. 3) assigned to vibrations of cytidine residues adopting $\mathrm{C} 2^{\prime}$-endo/anti sugar pucker. Intensity of this mode drops at higher temperatures, indicating transformation in ribose structure following gradual loss of C2' endo/anti conformation. We have constructed temperature profiles of the differential band intensity $\Delta I=I_{\mathrm{T}}-I_{2.5}$ (where $I_{\mathrm{T}}$ is the intensity at particular temperature $T$, and $I_{2.5}$ is the intensity at $2.5^{\circ} \mathrm{C}$ ) from the difference spectra in the $1200-1275-\mathrm{cm}^{-1}$ spectral region (Fig. 9). The negative sign of the differential intensity (Fig. 9, insets) reflects a decrease in the $1256-\mathrm{cm}^{-1}$ peak intensity at higher temperatures. The $\Delta I-T$ profiles for both WT and MT samples clearly exhibit two melting transitions. The exact lower $\left(T_{m}=23.6 \pm 1.6^{\circ} \mathrm{C}\right.$ and $19.7 \pm 2.8^{\circ} \mathrm{C}$ for WT and MT samples, respectively) and higher $\left(T_{m}=68.9 \pm 1.8^{\circ} \mathrm{C}\right.$ and $70.9 \pm 1.1^{\circ} \mathrm{C}$ for WT and MT samples, respectively)

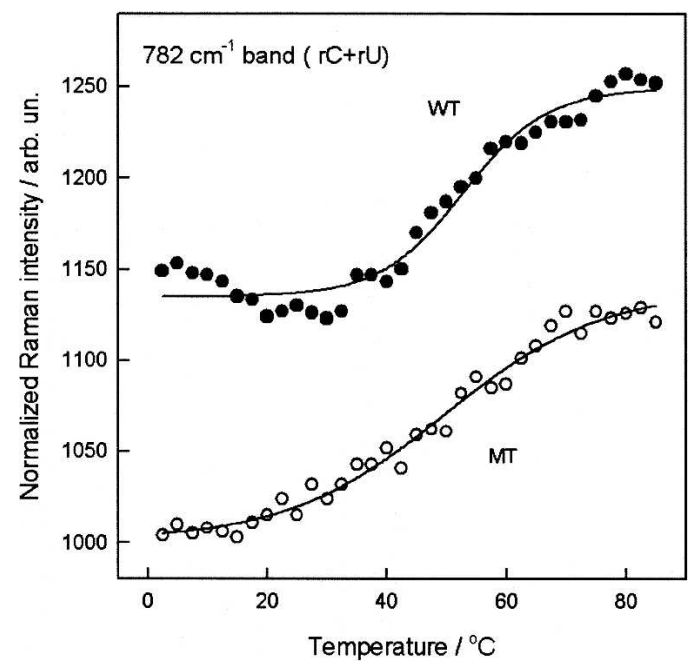

FIGURE 6. Temperature-dependent profile of the $782 \mathrm{~cm}^{-1}$ band, assigned to uracil and cytosine ring breathing vibration in the WT (filled circles) and the DKC-MT (open circles) hairpin forming oligonucleotides. Fitted curves are drawn by solid lines. 


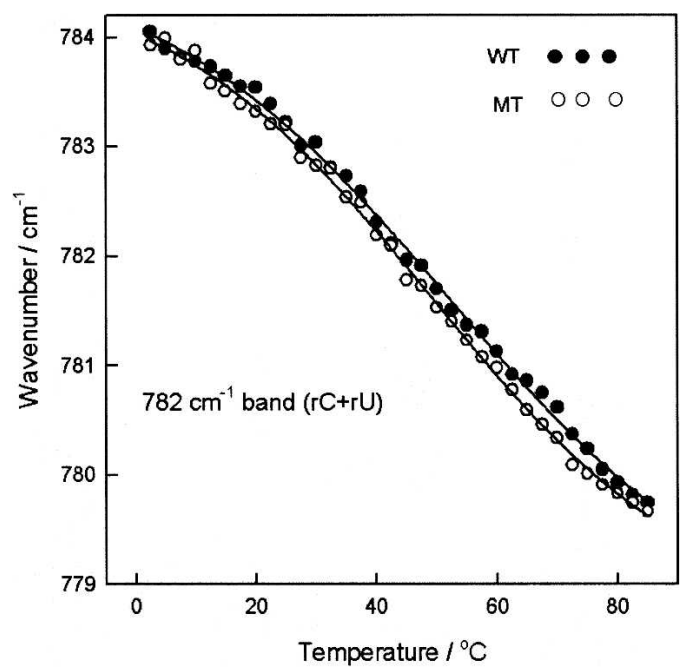

FIGURE 7. Temperature dependence of cytosine and uracil ring breathing mode frequency for the WT (filled circles) and DKC-MT (open circles) oligonucleotides. Band frequency was determined by decomposition of experimental spectral contour into components of the mixed Lorentzian-Gaussian shape.

temperature transition values were determined from the fitted curves (Fig. 9, lines). The lower temperature transition is associated with structural reorganization of the loop due to the subtle weakening in the hydrogen bonding interaction between nucleotides, and the higher temperature transition, most likely, demonstrates melting of the loop structure as a result of base destacking in the stem. Both transition temperatures are close for both WT and MT hairpin samples; however, the slight reduction in the low-temperature transition and increase in the hightemperature transition were observed resulting from the GC (107-108) $\rightarrow$ AG mutation.

The stem-loop pseudoknot hairpin (previously referred to as P2b) has two ordered domains, as previously shown by the UV melting experiments and NMR (Comolli et al. 2002; Theimer et al. 2003b). As shown in these studies, derivatives of the UV melting curves reveal two distinct transitions, at around $50^{\circ} \mathrm{C}\left(T_{m} 1\right)$ and another close to $79^{\circ} \mathrm{C}\left(T_{m} 2\right)$. NMR data provided the basis to assign $T_{m} 1$ to the melting of the loop and the second transition to the melting of the GCrich stem $\left(T_{m} 2\right)$. A similar study of the DKC-MT resulted in a slightly higher melting temperature for the loop $\left(T_{m} 1=\right.$ $54.2^{\circ} \mathrm{C}$ ), while stem melting occurred at a lower temperature $\left(T_{m} 2=77^{\circ} \mathrm{C}\right)$ (Comolli et al. 2002). This finding indicated that the DKC mutation provides additional stability to the loop region. A recent molecular dynamics simulation is in agreement with this conclusion; however, the whole hairpin structure experiences periodic structural rearrangements, possibly leading to interaction with the P3 region of the pseudoknot (Yingling and Shapiro 2005).

Our Raman results that show two thermal transitions confirm higher stability in the pentaloop region of the WT 30-mer relative to the DKC-MT (Fig. 9). Higher $T_{m}$ was also found for the intensity of the A-form marker band of the WT structure at $812 \mathrm{~cm}^{-1}$, suggesting stem destabilization in the DKC-MT. Raman hypochromism and frequency shift of the $782-\mathrm{cm}^{-1}$ band that predominantly reflects $\mathrm{rC}$ stacking interactions in the hairpin stem demonstrated gradual $\mathrm{H}$-bonding weakening at the pyrimidine ring imino and amino sites (Figs. 6, 7). The initial theory of Raman hypochromism (Peticolas 1995) predicted that all the bands in a Raman spectrum of a nucleic acid should change as the square of the UV absorbance in going from ordered to the melted form. This was not observed experimentally, and it seems likely that changes in the base stacking and hydrogen bonding in RNA may well lead to increasing or decreasing Raman intensities on increasing order. Therefore, direct comparison of UV melting and Raman profiles at present may only be justified for short model structures (Baumruk et al. 2001). Our study demonstrates that Raman band intensities and frequencies, previously assigned to specific bases or conformational RNA markers, can be used to probe subtle structural features of physiologically relevant telomerase hairpin sequences. Given the intrinsic Raman band parameter sensitivity to temperature variation, further studies would be required in order to establish unambiguous structural assignments to measured temperature dependencies.

\section{MATERIALS AND METHODS}

\section{RNA oligonucleotides}

Synthetic RNA oligonucleotides were obtained from Dharmacon Inc. (Lafayette Co.) produced using 2'-ACE chemistry, PAGE

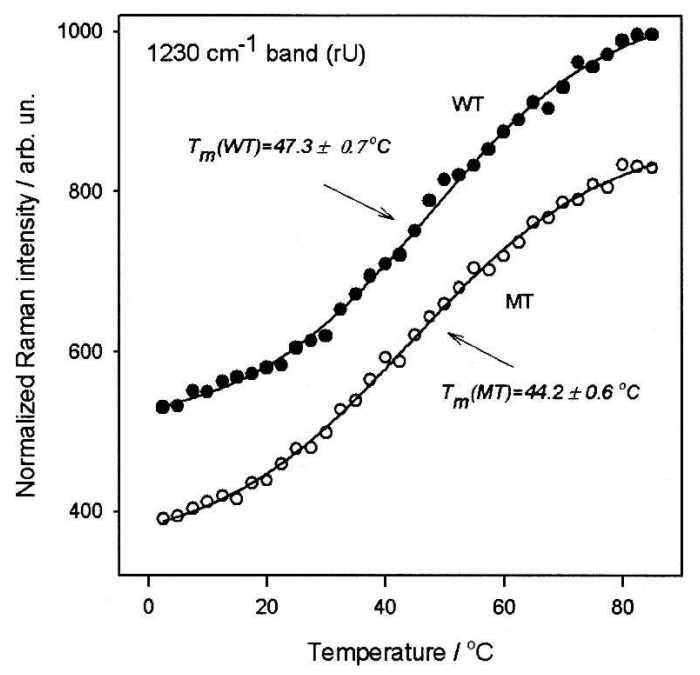

FIGURE 8. Temperature-dependent profiles of the $1230 \mathrm{~cm}^{-1}$ band associated with in-plane uracil ring vibration in the WT (filled circles) and DKC-MT (open circles) oligonucleotides. 


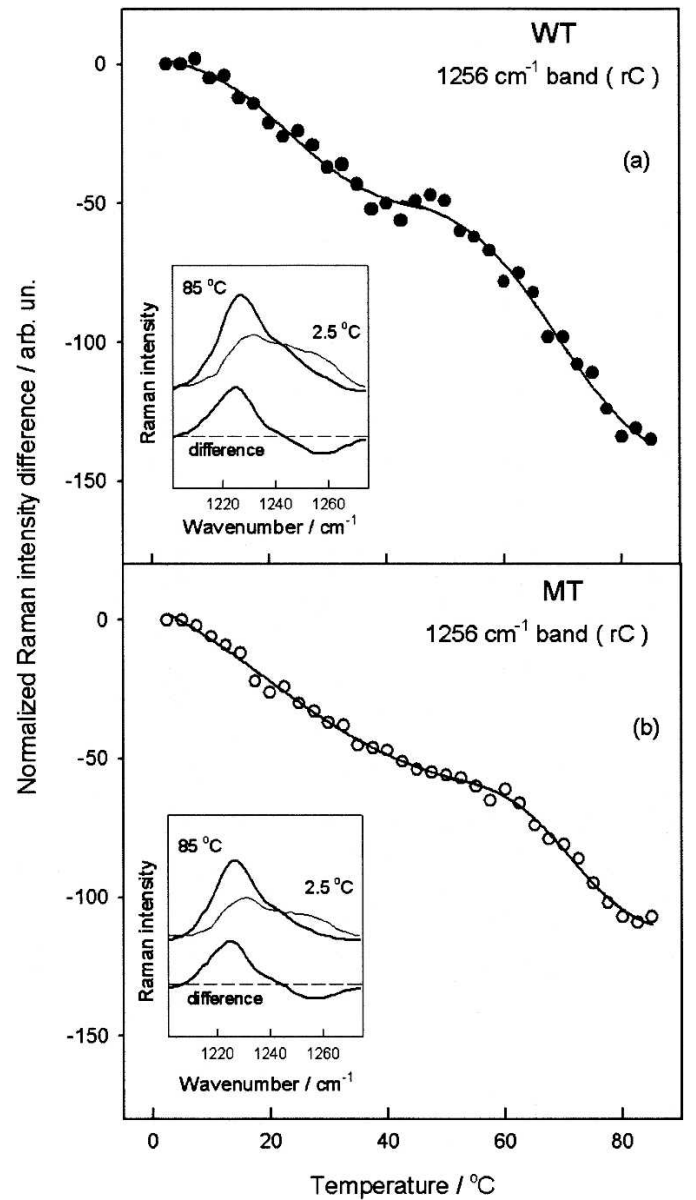

FIGURE 9. Temperature-dependent profiles of the $1256 \mathrm{~cm}^{-1}$ Raman band, assigned to cytidine nucleotides with $\mathrm{C} 2$ '-endo/anti sugar puckers, for the WT $(A)$ and DKC-MT $(B)$ hairpin forming oligonucleotides. Insets show the portion of Raman spectra in the $1200-1275 \mathrm{~cm}^{-1}$ interval at extreme temperatures and the difference that was used for the estimation of $1256 \mathrm{~cm}^{-1}$ band intensity.

purified (90\%-95\%) and verified by mass spectrometry as described previously (Scaringe et al. 1998). The oligonucleotides were obtained in the $2^{\prime}$ ACE protected form in order to protect against nuclease degradation during shipment and brief storage at $-20^{\circ} \mathrm{C} ; 3.3 \mathrm{mg}(350 \mathrm{nmol})$ of the lyophilized powder was dissolved in $0.8 \mathrm{~mL}$ deprotection buffer $(100 \mathrm{mmol} / \mathrm{L}$ acetic acid $\mathrm{pH} 3.8)$, incubated at $60^{\circ} \mathrm{C}$ for $30 \mathrm{~min}$, and rotovaporated to dryness according to instructions. The dry form was redissolved in $0.1 \mathrm{~mL}$ of $10 \mathrm{mmol} / \mathrm{L}$ sodium phosphate buffer $\mathrm{pH} \mathrm{7.0,} \mathrm{containing}$ $0.1 \mathrm{mmol} / \mathrm{L}$ EDTA to yield a final concentration of $3.5 \mathrm{mmol} / \mathrm{L}$. Capillary electrophoresis of the oligonucleotides under these conditions indicated $<20 \%$ association to dimer and above.

\section{Raman spectroscopy}

Raman spectra were acquired using a high efficiency transmission grating based spectrograph system (Holospec f 1.8, Kaiser optical Systems, Inc.) outfitted with a back illuminated CCD detector (Apogee Instruments, Inc.). The entrance slit of the spectrograph was set at $25 \mu \mathrm{m}$, which established a spectral width of about $3.7 \mathrm{~cm}^{-1}$ in the vicinity of $1500 \mathrm{~cm}^{-1}$. Spectra were excited with $647.1 \mathrm{~nm}$ line from Innova $300 \mathrm{Kr}$ laser (Coherent) using incident power at the sample of about $150 \mathrm{~mW}$. RNA samples were placed in sealed $10 \mu \mathrm{L}$ capillaries (Kimax, Kimble Glass Inc.), and were temperature controlled within $0.1^{\circ}$ in a modified UV-VIS sample holder (Quantum Northwest). Samples were equilibrated for $10 \mathrm{~min}$ at each temperature prior to spectra acquisition. Data was collected for $50 \mathrm{sec}$ with no further smoothing. Band intensity was normalized relative to the water bending mode at $1640 \mathrm{~cm}^{-1}(\delta[\mathrm{HOH}])$. Spectrometer calibration was checked at each temperature relative to several Kr plasma lines, which appeared after the removal of the laser line filter. The overlapped bands were digitally decomposed into the components of mixed Lorentzian-Gaussian shape. Spectral analysis was performed with Grams/386 software package (Version 2.04A, Galactic, Thermoelectron, Inc.). Raman spectra were acquired in the temperature range from $2.5^{\circ} \mathrm{C}$ to $85^{\circ} \mathrm{C}$ with a $2.5^{\circ} \mathrm{C}$ increment. Spectral changes were completely reversible as checked by acquisitions during cooling. Standard errors are given as \pm 1 standard deviation.

Received June 7, 2006; accepted September 26, 2006.

\section{REFERENCES}

Abdelkafi, M., Leulliot, N., Ghomi, M., Herve du Penhoat, C., Namane, A., Gouyette, C., Huynh-Dinh, T., Baumruk, V., and Turpin, P.Y. 1997a. Thermodynamic and structural properties of r(ACC) as revealed by ultraviolet electronic absorption, circular dichroism, 1H-NMR spectroscopy and Monte Carlo simulations. J. Biomol. Struct. Dyn. 409: 241-245.

Abdelkafi, M., Ghomi, M., Turpin, P.Y., Baumruk, V., Herve du Penhoat, C., Lampire, O., Bouchemal-Chibani, N., Goyer, P., Namane, A., Gouyette, C., et al. 1997b. Common structural features of UUCG and UACG tetraloops in very short hairpins determined by UV absorption, Raman, IR and NMR spectroscopies. J. Biomol. Struct. Dyn. 14: 579-593.

Abdelkafi, M., Leulliot, N., Baumruk, V., Bednarova, L., Turpin, P.Y., Namane, A., Gouyette, C., Huynh-Dinh, T., and Ghomi, M. 1998. Structural features of the UCCG and UGCG tetraloops in very short hairpins as evidenced by optical spectroscopy. Biochemistry 37: 7878-7884.

Allsopp, R.C., Vaziri, H., Patterson, C., Goldstein, S., Yonglai, E.V., Futcher, A.B., Greider, C.W., and Harley, C.B. 1992. Telomere length predicts replicative capacity of human fibroblasts. Proc. Natl. Acad. Sci. 89: 10114-10118.

Baumruk, V., Gouyette, C., Huyh-Dinh, T., Sun, J.S., and Ghomi, M. 2001. Comparison between CUUG and UUCG tetraloops: Thermodynamic stability and structural features analyzed by UV absorption and vibrational spectroscopy. Nucleic Acids Res. 29: 4089-4096.

Benevides, J.M. and Thomas, G.J. 1983. Characterization of DNA structures by Raman spectroscopy: High-salt and low-salt forms of double helical poly (dG-dC) in $\mathrm{H}_{2} \mathrm{O}$ and $\mathrm{D}_{2} \mathrm{O}$ solutions and application to B, Z and A-DNA. Nucleic Acids Res. 11: 5747-5761.

Blackburn, E.H. 1991. Structure and function of telomeres. Nature 350: 569-573.

Chen, H.-L. and Greider, C.W. 2005. Functional analysis of the pseudoknot structure in human telomerase RNA. Proc. Natl. Acad. Sci. 102: 8080-8085.

Chen, H.-L., Blasco, M.A., and Greider, C.W. 2000. Secondary structure of vertebrate telomerase RNA. Cell 100: 503-514.

Comolli, L.R., Smirnov, I., Xu, L., Blackburn, E.H., and James, T.L. 2002. A molecular switch underlies a human telomerase disease. Proc. Natl. Acad. Sci. 99: 16998-17003. 
Dohy, D., Ghomi, M., and Taillandier, E. 1989. Interpretation of DNA vibration modes: III-The behaviour of the sugar pucker vibration modes as a function of its pseudorotation parameters. J. Biomol. Struct. Dyn. 6: 741-754.

Kim, N.W., Piatyszek, M.A., Prowse, K.R., Harley, C.B., West, M.D., Ho, P.L., Coviello, G.M., Wright, W.E., Weinrich, S.L., and Shay, J.W. 1994. Specific association of human telomerase activity with immortal cells and cancer. Science 266: 2011-2015.

Leulliot, N., Baumruk, V., Abdelkafi, M., Turpin, P.Y., Namane, A., Gouyette, C., Tam, H.D., and Ghomi, M. 1999a. Unusual nucleotide conformations in GNRA and UNCG type tetraloop hairpins: Evidence from Raman markers assignments. Nucleic Acids Res. 27: 1398-1404.

Leulliot, N., Ghomi, M., Jobic, H., Bouloussa, O., Baumruk, V., and Coulombeau, C. 1999b. Ground state properties of the nucleic acid constituents studied by density functional calculations. 2 . Comparison between calculated and experimental vibrational spectra of Uridine and Cytidine. J. Phys. Chem. B. 103: 1093410944.

Li, T., Johnson, J.E., and Thomas, Jr., G.J. 1993. Raman dynamic probe of hydrogen exchange in Bean Pod Mottle virus: Basespecific retardation of exchange in packaged ssRNA. Biophys. J. 65: 1963-1972.

Martin-Rivera, L. and Blasco, M.A. 2001. Identification of functional domains and dominant negative mutations in vertebrate telomerase RNA using an in vivo reconstitution system. J. Biol. Chem. 276: 5856-5865.

Peticolas, W.L. 1995. Raman spectroscopy of DNA and proteins. Methods Enzymol. 246: 389-416.
Scaringe, S.A., Wincott, F.E., and Caruthers, M.H. 1998. Novel RNA synthesis method using $5^{\prime}$-silyl-2'-orthoester protecting groups. J. Chem. Soc. 120: 11820-11821.

Small, E.W., Brown, K.G., and Peticolas, W.L. 1972. Structural changes in t-RNA from changes in the Raman scattering intensities. Biopolymers 11: 1209-1215.

Theimer, C.A., Finger, L.D., and Feigon, J. 2003a. YNMG tetraloop formation by a dyskeratosis congenital mutation in human telomerase RNA. RNA 9: 1446-1455.

Theimer, C.A., Finger, L.D., Trantirek, L., and Feigon, J. 2003b. Mutations linked to dyskeratosis congenital cause changes in the structural equilibrium in telomerase RNA. Proc. Natl. Acad. Sci. 100: 449-454.

Theimer, C.A., Blois, C.A., and Feigon, J. 2005. Structure of the human telomerase RNA pseudoknot reveals conserved tertiary interactions essential for function. Mol. Cell 17: 671-682.

Thomas, G.A. and Peticolas, W.L. 1983. Fluctuations in nucleic acid conformations 2. Raman spectroscopic evidence of varying ring pucker in A-T Polynucleotides. J. Am. Chem. Soc. 105: 993-996.

Thomas, G.J. 1999. Raman spectroscopy of protein and nucleic acid assemblies. Annu. Rev. Biophys. Biomol. Struct. 28: 1-27.

Thomas, G.J. and Tsuboi, M. 1993. Raman spectroscopy of nucleic acids and their complexes. Adv. Biophys. Chem. 3: 1-70.

Trulson, M.A., Cruz, P., Puglisi, J.D., Tinoco, Jr., I., and Mathies, R.A. 1987. Raman spectroscopic study of left-handed Z-RNA. Biochemistry 26: 8624-8630.

Yingling, Y.G. and Shapiro, B.A. 2005. Dynamic behavior of the telomerase RNA hairpin structure and its relationship to dyskeratosis congenita. J. Mol. Biol. 348: 27-42. 

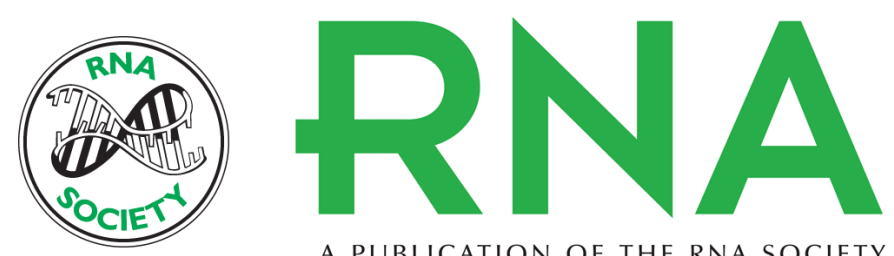

A PUBLICATION OF THE RNA SOCIETY

\section{Conformational analysis of the telomerase RNA pseudoknot hairpin by Raman spectroscopy}

Vytas Reipa, Gediminas Niaura and Donald H. Atha

RNA 2007 13: 108-115 originally published online November 21, 2006

Access the most recent version at doi:10.1261/rna.182607

$\begin{array}{ll}\text { References } & \begin{array}{l}\text { This article cites } 26 \text { articles, } 7 \text { of which can be accessed free at: } \\ \text { http://rnajournal.cshlp.org/content/13/1/108.full.html\#ref-list-1 }\end{array}\end{array}$

License

Email Alerting Receive free email alerts when new articles cite this article - sign up in the box at the Service top right corner of the article or click here.

To subscribe to RNA go to:

http://rnajournal.cshlp.org/subscriptions 